\title{
RESPIRATORY SARCOPENIA AND SARCOPENIC RESPIRATORY DISABILITY: CONCEPTS, DIAGNOSIS, AND TREATMENT
}

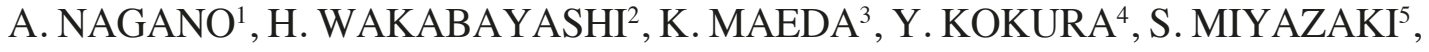 \\ T. MORI ${ }^{6}$, D. FUJIWARA ${ }^{7}$

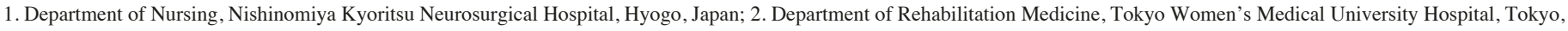
Japan; 3. Department of Geriatric Medicine, National Center for Geriatrics and Gerontology, Aichi, Japan; 4. Department of Clinical Nutrition, Keiju Medical Center, Ishikawa, Japan; 5. Rehabilitation Center, KKR Takamatsu Hospital, Takamatsu, Japan; 6. Department of Oral and Maxillofacial Surgery, Southern Tohoku General Hospital, Koriyama, Japan; 7. Department of Rehabilitation Medicine, Saka General Hospital, Miyagi, Japan. Corresponding author: Hidetaka Wakabayashi, MD, PhD, Department of Rehabilitation Medicine, Tokyo Women's Medical University Hospital, 8-1, Kawada-cho, Shinjuku-ku, Tokyo, Japan. Code; 162-0054, Tel: +81-3-3353-8111, Fax: +81-3-5269-7639, E-mail: noventurenoglory@gmail.com
\end{abstract}

\begin{abstract}
The condition of muscle fiber atrophy and weakness that occurs in respiratory muscles along with systemic skeletal muscle with age is known as respiratory sarcopenia. The Japanese Working Group of Respiratory Sarcopenia of the Japanese Association of Rehabilitation Nutrition narratively reviews these areas, and proposes the concept and diagnostic criteria. We have defined respiratory sarcopenia as "wholebody sarcopenia and low respiratory muscle mass followed by low respiratory muscle strength and/or low respiratory function." Respiratory sarcopenia can be caused by various factors such as aging, decreased activity, undernutrition, disease, cachexia, and iatrogenic causes. We have also created an algorithm for diagnosing respiratory sarcopenia. Respiratory function decreases with age in healthy older people, along with low respiratory muscle mass and strength. We have created a new term, "Presbypnea," meaning a decline in respiratory function with aging. Minor functional respiratory disability due to aging, such as that indicated by a modified Medical Research Council level 1 (troubled by shortness of breath when hurrying or walking straight up hill), is an indicator of presbypnea. We also define sarcopenic respiratory disability as "a disability with deteriorated respiratory function that results from respiratory sarcopenia." Sarcopenic respiratory disability is diagnosed if respiratory sarcopenia is present with functional disability. Cases of respiratory sarcopenia without functional disability are diagnosed as "at risk of sarcopenic respiratory disability." Functional disability is defined as a modified Medical Research Council grade of 2 or more. Rehabilitation nutrition, treatment that combines rehabilitation and nutritional management, may be adequate to prevent and treat respiratory sarcopenia and sarcopenic respiratory disability.
\end{abstract}

Key words: Rehabilitation nutrition, secondary sarcopenia, muscle wasting, aging, respiration.

\section{Introduction}

The condition of muscle fiber atrophy and weakness that occurs in respiratory muscles along with systemic skeletal muscle with aging is known as respiratory sarcopenia (1-4). Respiratory sarcopenia causes deterioration of respiratory force generation (5) and pulmonary function $(3,6)$, which then adversely affect activities of daily living and quality of life $(3,5-7)$. Therefore, it is important that medical professionals become aware of respiratory sarcopenia. However, the concept of and diagnostic criteria for respiratory sarcopenia have not been discussed before. Therefore, the Japanese Working Group of Respiratory Sarcopenia of the Japanese Association of Rehabilitation Nutrition has developed a narrative review of these areas.

Aging causes a decrease in respiratory muscle mass, weakness in respiratory muscle strength, and a decline in respiratory function. However, there has been no definition or term for a decline in respiratory function due to aging. Therefore, we termed a decline in respiratory function with aging as "presbypnea", which is created by combining "presby-" meaning geriatric and "-pnea" meaning respiratory (Table1). Minor respiratory function disability, such as that Received November 24, 2020 represented by a modified Medical Research Council (Modified MRC) (8) level of 1 , is an indicator of presbypnea.

Respiratory sarcopenia is caused by various factors such as aging, decreased activity, undernutrition, hypoxic stress, disease, and cachexia (6). Diaphragm and intercostal muscles are the main respiratory muscles (9) and respiratory muscle mass can be measured by computed tomography $(\mathrm{CT})(10,11)$ or ultrasonography (12-14). Low respiratory muscle strength is commonly evaluated using peak expiratory rate (15) or maximum respiratory pressure (16). Kera et al. (1) have given a definition of respiratory sarcopenia using peak expiratory flow rate (PEFR) and have adopted a PEFR value 1 standard deviation below the mean as the cut-off value for the diagnosis. However, considering that whole-body sarcopenia in Asia is defined as "age-related loss of skeletal muscle mass plus loss of muscle strength and/or reduced physical performance", (17) the criteria for respiratory sarcopenia should include not only loss of respiratory muscle strength but also loss of respiratory muscle mass. Thus, in this article, we define respiratory sarcopenia as "whole-body sarcopenia and low respiratory muscle mass followed by low respiratory muscle strength and/ or deteriorated respiratory function." Moreover, we propose an algorithm for the diagnosis of respiratory sarcopenia.
Published online January 11, 2021, http://10.1007/s12603-021-1587-5 
Table 1

Terms and definitions

\begin{tabular}{|c|c|}
\hline Terms & Definitions \\
\hline \multirow[t]{2}{*}{ Presbypnea } & A decline in respiratory function with aging. \\
\hline & $\begin{array}{l}\text { Minor functional respiratory disability, such as that represented by a modified Medical Research Council } \\
\text { level of } 1 \text {, is an indicator of presbypnea. }\end{array}$ \\
\hline \multirow[t]{2}{*}{ Respiratory sarcopenia } & $\begin{array}{l}\text { Whole-body sarcopenia and low respiratory muscle mass followed by low respiratory muscle strength and/ } \\
\text { or deteriorated respiratory function. }\end{array}$ \\
\hline & $\begin{array}{l}\text { Cases where other criteria are met without the measurement of respiratory muscle mass are diagnosed as } \\
\text { "probable respiratory sarcopenia." Cases with the possibility of diseases that are causative of respiratory } \\
\text { dysfunction are diagnosed as "possible respiratory sarcopenia." }\end{array}$ \\
\hline \multirow[t]{2}{*}{ Sarcopenic respiratory disability } & Disability with deteriorated respiratory function due to respiratory sarcopenia. \\
\hline & $\begin{array}{l}\text { Cases of respiratory sarcopenia without functional disability are diagnosed as "at risk of sarcopenic } \\
\text { respiratory disability." When functional disability is present in the absence of respiratory sarcopenia, the } \\
\text { cause is considered to be another respiratory disease. }\end{array}$ \\
\hline
\end{tabular}

Discussions of respiratory disability have focused on oxygen consumption or its impact on disability in terms of work rather than its impact on daily living (18-20). However, other conditions such as functional disability and limitations in activity participation caused by respiratory sarcopenia deserve focus and should be defined. We define "sarcopenic respiratory disability" as a disability with deteriorated respiratory function due to respiratory sarcopenia.

This article describes age-related respiratory decline, the diagnostic criteria for respiratory sarcopenia and sarcopenic respiratory disability, and rehabilitation nutrition management as a treatment.

\section{Age-related respiratory sarcopenia}

Respiratory function decreases with age in healthy older people $(21,22)$. Furthermore, the risk of respiratory infections and complications also increases with age (23-25). Age-related respiratory sarcopenia may cause respiratory infections and complications.

\section{Aging and respiratory muscles}

Respiratory muscle strength and muscle mass decrease with age, resulting in the development of diaphragm muscle sarcopenia. Age and sex are related to respiratory muscle strength (26), and respiratory muscle strength also decreases with age $(27,28)$. Intercostal muscle mass also decreases with age (29). The diaphragm is the most important muscle used for breathing and it is also affected by aging and sarcopenia (30). In an elderly population, transdiaphragmatic pressure, an indicator of diaphragmatic muscle activity, decreases by $20-41 \%$, with a decline in overall respiratory muscle strength of $30 \%$ (30). Older mice have been shown to suffer a loss of maximal diaphragm muscle force and decreased muscle fiber type IIx and/or IIb size and develop diaphragm muscle sarcopenia (6). In human autopsy cases, advancing age has been associated with histopathologically abnormal findings in diaphragm structure, including small diaphragm size or shape and loss of cytoplasmic integrity (31).

\section{Whole-body muscle, respiratory muscle, and function}

Respiratory muscle strength and respiratory function are related to whole-body muscle mass and strength. The skeletal muscle mass index correlates with maximal inspiratory pressure (MIP) and maximal expiratory pressure (MEP) in older people (32). Diaphragm weight in autopsy cases with a mean age of $70.8 \pm 16.8$ years has shown a significantly positive correlation with lean body mass measured during life (33). For whole-body muscle mass and respiratory function, appendicular skeletal muscle mass (34) and skeletal muscle area of the third lumbar vertebrae level (35) are associated with forced vital capacity (FVC) and one-second forced expiratory volume (FEV1), respectively. Hand-grip strength is independently associated with MIP and MEP in older people (32). In communitydwelling older women without chronic diseases or pulmonary diseases, higher hand-grip strength is associated with higher FVC and FEV1. Additionally, the adjusted odds ratio of impaired pulmonary function is greater for participants in the first quartile of hand-grip strength than for those in the fourth quartile (36). Furthermore, hand-grip strength has been associated with MIP and peak cough flow in male nursing home residents (37). MIP also correlates with knee extensor strength and hand-grip strength in both males and females, including young adults (38).

\section{Physical performance, respiratory muscles, and function}

Low physical performance is related to low respiratory muscle strength and respiratory function. In older people, low inspiratory muscle endurance is associated with the low walking performance (27). The time taken to perform a task in 


\section{THE JOURNAL OF NUTRITION, HEALTH \& AGING}

chair stand tests shows a positive correlation with FVC, FEV1, and peak expiratory flow (PEF) (39). Physical performance, balance, and gait scores in low PEF group were significantly lower compared to a normal PEF group (40). Moreover, higher levels of respiratory muscle strength are associated with a slower rate of decline in mobility (7).

\section{Sarcopenia, frailty, respiratory muscles, and function}

Respiratory muscle strength, diaphragmatic thickness, and respiratory function are impaired in older adults with sarcopenia or frailty. MIP, MEP (5), and PEFR (41) have been used to discriminate sarcopenia in community-dwelling elderly. Sarcopenic patients have a thinner diaphragm and lower PEFR compared to non-sarcopenic patients (42). Frail and pre-frail older adults present with significantly lower MIP and MEP compared to non-frail older people. Therefore, respiratory muscle strength may be useful for discriminating frailty (43). Besides, decreased PEFR is a risk for frailty and can be a marker of general robustness in older people (44). These suggest that sarcopenia and/or frailty in older people are associated with respiratory sarcopenia.

\section{Disease-related respiratory sarcopenia}

\section{Relationship between respiratory sarcopenia and inflammation}

Skeletal muscle is impaired by systemic inflammation. Increased production of inflammatory cytokines such as TNF$\alpha$, IL-1, IL-6, IFN- $\gamma$ is one of the causes of catabolism in skeletal muscle $(45,46)$. In cases of influenza, inflammatory endocrine signals caused by damaged lungs activate the signaling pathway of muscles, inducing dysfunction (47). Since these mediators of inflammation are related, the same phenomenon could occur with bacterial infections and viral infections, including coronavirus disease 2019 (COVID-19).

The inflammatory response due to infection also causes a decrease in the function of the diaphragm, as one of the skeletal muscles. Endotoxin induces weakening of the diaphragm through the activation of caspase 3 in the diaphragm (48). Also, in the process promoting protein catalysis, the oxidative stress of mitochondria is associated with diaphragm atrophy and induced dysfunction in patients with severe infection (49). Inflammation of the respiratory muscles becomes a promoter of respiratory sarcopenia, which can then be one of the factors causing respiratory dysfunction.

\section{Factors promoting disease-related respiratory sarcopenia}

Factors promoting sarcopenia, such as disease, cachexia, and undernutrition, may cause dysfunction of the respiratory muscles. Aspiration pneumonia is an acute inflammatory disease that induces muscle atrophy of the respiratory and swallowing systems (50). The cycle of inflammation and sarcopenia has been proposed as follows: Okazaki et al. reported that inflammation caused by aspiration pneumonia can cause undernutrition and sarcopenia, which can be a risk for aspiration pneumonia (51). Chronic obstructive pulmonary disease (COPD) is also a chronic inflammatory disease. In COPD patients, fibers degenerated not only in the diaphragm but also in appendicular skeletal muscle (52). Cachexia caused by cancer is associated with atrophy of the appendicular skeletal muscle and respiratory muscles (53). The function of the diaphragm has also been reportedly reduced by undernutrition (54).

Ventilators also impair respiratory muscles. Muscle strength and muscle mass of the diaphragm have been reported to decrease with mechanically ventilated conditions (55-57). In addition, Goligher et al. (14) evaluated patients whose diaphragm was atrophied by ventilator mounting. The reported condition of the diaphragm was associated with clinical outcomes such as days on mechanical ventilation and hospitalization periods in intensive care units. Acute and chronic inflammation, undernutrition, cachexia, and inactivity may become promoting factors for respiratory sarcopenia and respiratory dysfunction.

\section{The vicious cycle of respiratory sarcopenia and sarcopenic respiratory disability}

Respiratory sarcopenia, like whole-body sarcopenia, is caused by aging, low activity, undernutrition, and inflammation from disease. In age-related diaphragmatic sarcopenia, the selective atrophy of type IIx and/or IIb muscle fibers results in a reduction in forced ventilation and coughing ability mainly related to airway clearance (3). These functional changes may contribute to an increased risk of respiratory infections and complications in older adults (58). Acute inflammation associated with acute diseases such as infections (50) and chronic inflammation associated with chronic diseases such as cancer (59) cause respiratory muscle sarcopenia. Loss of appetite and reduced nutritional intake associated with aging or inflammation can cause respiratory muscle sarcopenia due to undernutrition (54). Age-related decline of physical activity may cause respiratory muscle sarcopenia due to low activity (60). The combination of these multiple factors causes and worsens respiratory sarcopenia.

Sarcopenic respiratory disability occurs as a result of a vicious cycle of respiratory sarcopenia (Figure 1). Respiratory sarcopenia promotes low activity, undernutrition, and inflammation. These etiologies of sarcopenia exacerbate respiratory sarcopenia, causing functional disability. In sarcopenic respiratory disability, shortness of breath becomes apparent. Shortness of breath further contributes to the risk of respiratory infections and complications, decreased appetite and nutritional intake (61), and low physical activity (62). These factors, in turn, exacerbate respiratory sarcopenia and sarcopenic respiratory disability.

In patients under ventilator management, the difficulty of weaning from a ventilator may occur as a result of a vicious 
cycle of respiratory sarcopenia. Low diaphragm function caused by mechanical ventilation is known as ventilator-induced diaphragmatic dysfunction (63). Diaphragm inactivity with ventilator management leads to diaphragm atrophy (55). Acute inflammation associated with acute diseases such as respiratory infections leads to systemic and diaphragmatic muscle atrophy (50). Undernutrition is caused by increased energy demand associated with acute inflammation and reduced energy supply associated inadequate nutritional management. Undernutrition can also lead to systemic and diaphragmatic muscle atrophy. Neuromuscular blockers (64) and corticosteroids (65) used during ventilator management can lead to contractile dysfunction of the diaphragm. Diaphragm atrophy and reduced contractile function increase the risk of reintubation and tracheostomy, prolong ventilation, and increase hospital mortality (66). Prolonged ventilation promotes low activity, undernutrition, and inflammation, and exacerbates diaphragm atrophy and contractile dysfunction.

\section{Figure 1}

Vicious cycle of respiratory sarcopenia and sarcopenic respiratory disability and intervention of combined exercise and nutrition

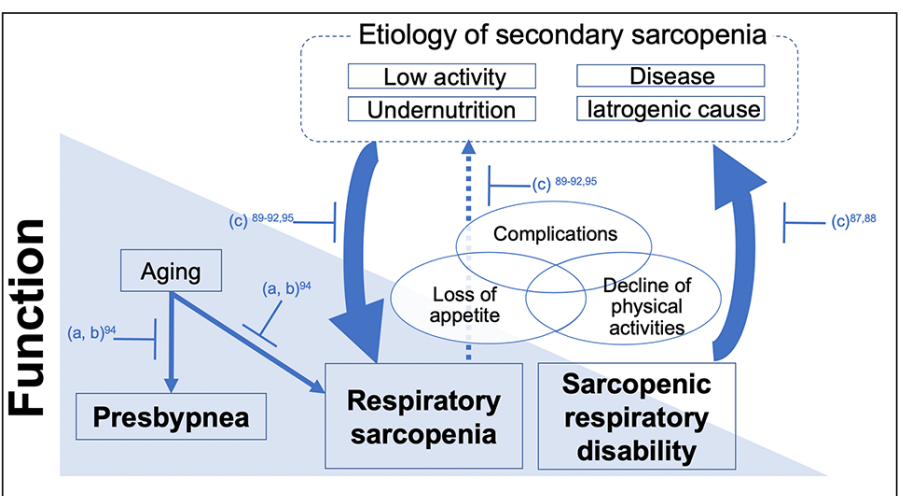

Aging, low activity, undernutrition, inflammation, and iatrogenic causes are etiologies of whole-body sarcopenia and respiratory sarcopenia. Whole-body sarcopenia and respiratory sarcopenia further exacerbate low activity, undernutrition, and inflammation. The vicious cycle results in sarcopenic respiratory disability. Rehabilitation nutrition is presumed to be effective for treating respiratory sarcopenia and sarcopenic respiratory disability, and may break the vicious cycle of respiratory sarcopenia and sarcopenic respiratory disability. a) Exercise, b) Nutrition, c) Exercise + Nutrition (Rehabilitation Nutrition)

\section{Diagnosis of respiratory sarcopenia and sarcopenic respiratory disability}

\section{Diagnosis of respiratory sarcopenia}

Respiratory sarcopenia is defined as "whole-body sarcopenia and low respiratory muscle mass followed by low respiratory muscle strength and/or deteriorated respiratory function" (Table 1). The algorithm for diagnosing respiratory sarcopenia is shown in Figure 2. The criteria reported by the Asian Working Group of Sarcopenia 2019 (17) and the position paper for sarcopenic dysphagia (67) may be adopted for diagnosing whole-body sarcopenia in our algorithm. "Definite sarcopenia" is diagnosed when whole-body sarcopenia with low respiratory muscle mass is identified followed by low respiratory muscle strength and/or deteriorated respiratory function with the exclusion of obvious disease causative of low respiratory muscle mass: lung tumors, pulmonary edema, bronchiectasis, diaphragmatic paralysis, neuromuscular diseases, and congenital morphological abnormalities. CT $(10,11)$ and ultrasonography (12-14) are common methods used to assess respiratory muscle mass. Since, at this point, quantitative measurement of respiratory muscle mass is difficult in clinical settings, it is hard to diagnose a decrease in respiratory muscle mass. Cases where other criteria are met alone (respiratory muscle mass measurement is excluded) are diagnosed as "probable respiratory sarcopenia." Besides, respiratory diseases such as COPD may also be accompanied by generalized sarcopenia and low respiratory muscle mass. However, it is difficult to determine whether the decline in respiratory function is due to disease or a decline in respiratory muscle strength and volume. Thus, cases with possible diseases causative of respiratory dysfunction are diagnosed as "possible respiratory sarcopenia."

\section{Figure 2}

A flow-chart for diagnosing respiratory sarcopenia

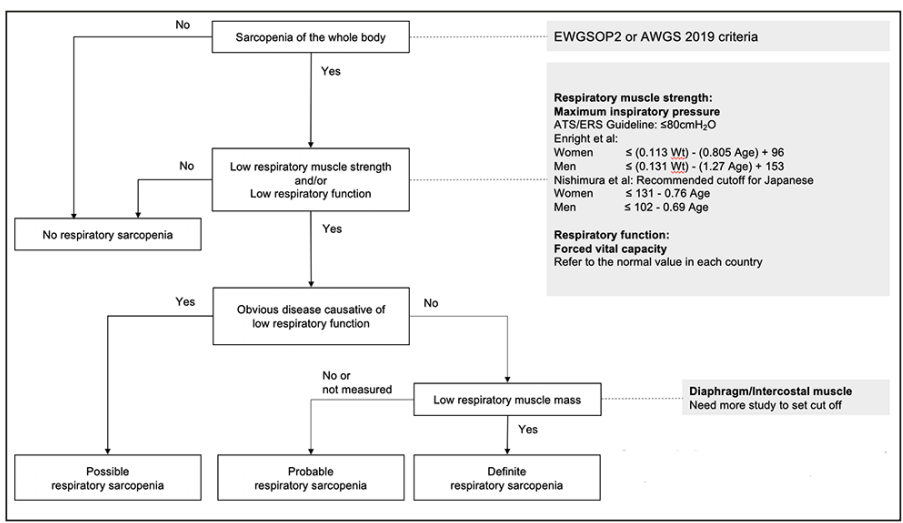

"Definite sarcopenia" is diagnosed when whole-body sarcopenia with low respiratory muscle mass is identified followed by low respiratory muscle strength and/or deteriorated respiratory function with the exclusion of obvious disease causative of low respiratory muscle mass. Cases where other criteria are met alone (respiratory muscle mass measurement is excluded) are diagnosed as "probable respiratory sarcopenia." Cases with possible diseases causative of respiratory dysfunction are diagnosed as "possible respiratory sarcopenia." Abbreviations: EWGSOP, European Working Group on Sarcopenia in Older People; AWGS, Asian Working Group of Sarcopenia; ATS/ERS, American Thoracic Society/European Respiratory Society; Wt, weight

As for respiratory muscle strength, MIP value may be adopted as a diagnostic criterion in the algorithm of respiratory sarcopenia. Indicators of respiratory muscle strength include MIP/MEP, maximum cough strength, and maximum sniff pressures (16). MIP and MEP are useful measurement methods of respiratory muscle strength in clinical settings $(9,68)$. In particular, MIP has a stronger association with skeletal muscle mass and muscle strength than to MEP (32), and also MIP is used to indicate ventilation failure. Thus, MIP may be adopted as a diagnostic criterion for respiratory sarcopenia. Guidelines 


\section{THE JOURNAL OF NUTRITION, HEALTH \& AGING}

from the American Thoracic Society/European Respiratory Society (ATS/ERS) (16) give a cut-off value for low respiratory muscle strength of $<$ PImax $80 \mathrm{cmH}_{2} \mathrm{O}$. Enright et al. (28) also presented an equation for estimating a reference value for MIP. In Japan, a reference value estimated using an equation by Nishimura et al. (69) is preferred, as an equation used for a western population may lead to overestimation in an Asian population due to differences in body size.

FVC may be adopted as a respiratory function in our algorithm. Vital capacity and FVC are common measurement methods for respiratory function. We adopted FVC as a measure of respiratory function, as FVC is associated with sarcopenia $(39,70)$. As with MIP, FVC varies by body size, so it is considered adaptable to local standards (21). In Japan, the reference value estimated using the LMS method is recommended for assessing respiratory function (22). Peak flow rate is another measure of respiratory function, and it is adopted as a definition of respiratory sarcopenia as reported by Kera et al. (1) However, as PFR is strongly affected by respiratory diseases such as COPD and asthma, we did not adopt it as a measure of respiratory sarcopenia.

Figure 3

Diagnosis of sarcopenic respiratory disability

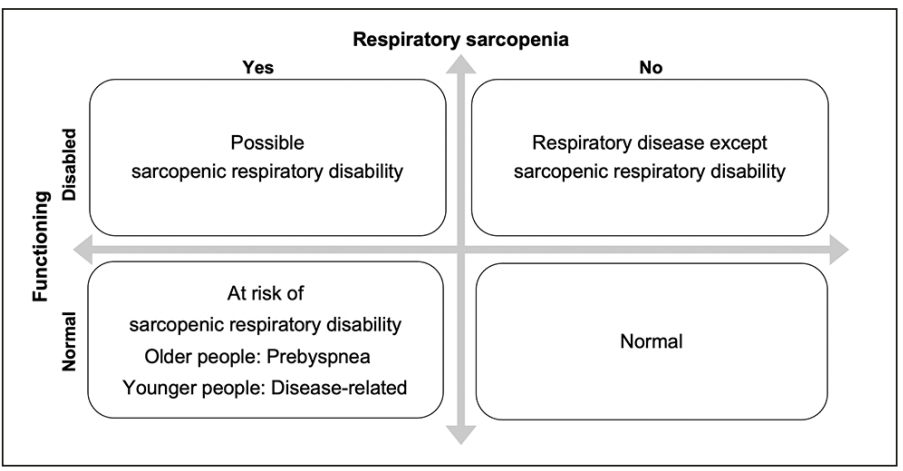

Sarcopenic respiratory disability is diagnosed as respiratory sarcopenia with functiona disability. Functional disability is assessed using a modified Medical Research Council of grade 2 or more. Cases of respiratory sarcopenia without functional disability are diagnosed as "at risk of sarcopenic respiratory disability." Presbypnea is a possible cause of sarcopenic respiratory disability in older people. On the other hand, respiratory diseases may be possible causes of sarcopenic respiratory disability in the young. When functional disability is present in the absence of respiratory sarcopenia, the cause is considered to be other respiratory diseases.

We have proposed the algorithm for diagnosing respiratory sarcopenia and presented some measures and cut-off values. However, there is a lack of evidence in specificity of the measures and its cut-off values. Further research is required to validate the algorithm in clinical settings.

\section{Diagnosis of sarcopenic respiratory disability}

Sarcopenic respiratory disability is defined as "disability with deteriorated respiratory function due to respiratory sarcopenia" (Table 1). Sarcopenic respiratory disability is specified as respiratory sarcopenia with functional disability (Figure 3). Cases of respiratory sarcopenia without functional disability are diagnosed as "at risk of sarcopenic respiratory disability," since the vicious cycle of respiratory sarcopenia may aggravate respiratory sarcopenia. Presbypnea is a possible cause of sarcopenic respiratory disability in older people. On the other hand, respiratory disease may be a possible cause of sarcopenic respiratory disability in the young. Moreover, when functional disability occurs in the absence of respiratory sarcopenia, functional disability may be caused by another respiratory disease.

Functional disability due to respiratory sarcopenia is assessed using a modified Medical Research Council (modified MRC) (8) score. The modified MRC is a globally standardized scale used to evaluate function related to dyspnea. The modified MRC is a five-level scale: Grade 0, not troubled with breathlessness except with strenuous exercise; Grade 1 , troubled by shortness of breath when hurrying or walking straight up hill; Grade 2, walks slower than people of the same age due to breathlessness or has to stop for breath when walking at own pace on a level surface; Grade 3, stops for breath after walking $100 \mathrm{~m}$ or after a few minutes on a level surface; Grade 4, too breathless to leave the house or breathless when dressing or undressing (8). For the diagnosis of sarcopenic respiratory disability, functional disability was assessed using a modified MRC of grade 2 or more. Dyspnea due to neuromuscular disease is not included in the criteria for sarcopenic respiratory disability, because it is associated with respiratory tract palsy rather than sarcopenia. Moreover, acute aggravation of respiratory diseases is not included as sarcopenic respiratory disability. However, the difficulty of weaning from a respirator after acute respiratory failure is considered a criteria for sarcopenic respiratory disability, since diaphragm inactivity with ventilator management leads to diaphragm atrophy (55) and causes respiratory dysfunction (63).

\section{Rehabilitation nutrition as a therapeutic strategy}

There are no previous studies that have investigated the effect of a therapeutic approach for respiratory sarcopenia and sarcopenic respiratory disability. Here, we propose a rehabilitation nutrition treatment (novel nutritional management using a combination of nutritional therapy and exercise) for respiratory sarcopenia and sarcopenic respiratory disability. This is based on the results of interventional studies in older adults with sarcopenia and patients with respiratory disease.

\section{Exercise intervention including respiratory rehabilitation}

Exercise intervention is presumed to be useful for respiratory sarcopenia and sarcopenic respiratory disability.

\section{Strength training of respiratory muscles}

Strength training of respiratory muscles may be effective in improving physical function, respiratory function, and muscle strength. Inspiratory muscle training improved dyspnea (Baseline Dyspnea Index), exercise capacity (6 min walk test 


\section{RESPIRATORY SARCOPENIA AND SARCOPENIC RESPIRATORY DISABILITY}

(6MWT)) in COPD (71), maximum expiratory pressure in the adult population (72), and skeletal muscle strength in older adults with sarcopenia (73). In addition, in patients with COVID-19, FEV1, FVC, FEV1 / FVC\%, DLCO\%, and 6MWT also improved with respiratory rehabilitation (74).

\section{Strength training of the lower limb}

Strength training of the lower limb increases muscle mass, muscle strength, and motor performance. In severely dyspneic individuals with COPD, lower-limb muscle training improves quadriceps muscle endurance, exercise performance, lowerlimb fat-free mass, exercise-induced symptoms of dyspnea, and fatigue compared to baseline (75). Lower limb resistance training improves muscle strength (isometric/isokinetic muscle evaluation) and motor endurance (6MWT) in patients with COPD (76). It also improves performance in a five-repetition sit-to-stand test compared to respiratory rehabilitation (76). In addition, after a squat exercise program, grip strength, knee extensor strength, and 3-min walk distance increased in patients with sarcopenia (77).

\section{Resistance training of the whole body}

Resistance training of the whole body is effective in improving physical function and increasing muscle strength and muscle mass. Resistance training of the whole body can increase the 6MWT, upper extremity endurance capacity, knee endurance, and knee strength more than the control group in patients with moderate-to-severe COPD (78). In geriatric people with sarcopenia, resistance training of the whole body resulted in higher appendicular skeletal muscle mass compared to baseline. Also, their high-sensitivity C-reactive protein levels were lower than they were at baseline. At follow-up, handgrip strength, back strength, and PEF were higher than in a control group (79).

\section{Combined aerobic and resistance training}

Aerobic and resistance exercise training is effective in improving exercise capacity, muscle mass, and muscle strength. Aerobic and resistance exercise training improved the 6MWT in lung transplant candidates (80). Combined aerobic and resistance exercise training increases rectus femoris thickness (81) and quadriceps muscle strength (82) in COPD patients. Exercise intervention may be useful for respiratory sarcopenia and sarcopenic respiratory disability.

\section{Nutritional intervention}

Nutritional intervention beneficially affects muscle mass, performance status, physical activity, respiratory muscle strength, and respiratory muscle function. In stable COPD patients, nutritional supplementation improves lean body mass $(83)$ and the 6MWT $(83,84)$. In addition, there were improvements in MIP and MEP (84). In lung cancer patients, oral nutritional supplement intervention showed a higher Karnofsky Performance Status and physical activity than a control (85). In older individuals with sarcopenia, nutritional intervention improves functional performance measured by walking time and maximum static expiratory force compared to placebo (86).

\section{Combined exercise and nutritional intervention}

Exercise and nutritional intervention may be useful for respiratory sarcopenia and sarcopenic respiratory disability. As interventions, high-intensity exercise training and nutritional supplementation had additional effects on skeletal muscle mass, quadriceps muscle strength, and cycle endurance time. Inspiratory muscle strength only improved in the intervention group (87). Uptake of nutritional supplementation during pulmonary rehabilitation improved quadriceps muscle strength, and inspiratory muscle function (88). Respiratory muscle rehabilitation, exercise, and enteral nutrition support increased MIP, MEP, and FVC (89).

\section{Rehabilitation Nutrition}

Rehabilitation nutrition is presumed to be effective for treating respiratory sarcopenia and sarcopenic respiratory disability. Rehabilitation nutrition is defined as that which is evaluated holistically by the International Classification of Functioning, Disability and Health, and the presence and cause of nutritional disorders, sarcopenia, and excessive or deficient nutritional intake. In several case reports, rehabilitation nutrition combined with adequate nutrition and aggressive rehabilitation contributed to increased muscle mass (90-92) and muscle strength $(91,92)$, and improved physical function (93) and sarcopenia (90). Rehabilitation nutrition can be practiced more effectively and comprehensively by using the rehabilitation nutrition care process, which is a systematic problem-solving method (94). In clinical practice guidelines for sarcopenia (95), regular exercise and proper nutritional intake may be effective in preventing the development of sarcopenia and is therefore recommended. In addition, compared with singular interventions, combined interventions, including comprehensive exercise-based treatment, such as resistance training and nutritional intervention, are more effective for improving sarcopenia and are recommended (96). Therefore, rehabilitation nutrition may break the vicious cycle of respiratory sarcopenia and sarcopenic respiratory disability (Figure 1). However, the ability of this approach to improve long term outcomes is not yet clear (96). Further research is required to verify the efficacy of rehabilitation nutrition for preventing or improving respiratory sarcopenia and sarcopenic respiratory disability.

\section{Conclusion}

Respiratory function decreases with age in healthy older people, for which we have created a new term, "presbypnea." Respiratory sarcopenia is characterized as whole-body sarcopenia with low respiratory muscle mass followed by low 


\section{THE JOURNAL OF NUTRITION, HEALTH \& AGING}

respiratory muscle strength and/or deteriorated respiratory function. Respiratory sarcopenia is caused by various factors such as aging, inactivity, undernutrition, disease, inflammation, and cachexia. Moreover, a vicious cycle of these factors worsens respiratory sarcopenia and causes sarcopenic respiratory disability. Respiratory muscle sarcopenia is not recognized in clinical practice due to a lack of concept and diagnostic criteria, but it may in fact be present in a number of cases. We have proposed an algorithm for diagnosing respiratory sarcopenia. Clinical diagnosis and rehabilitation nutrition interventions may improve function. It is important to increase clinical interest in respiratory sarcopenia and sarcopenic respiratory disability through research and clinical practice. Further research is required to validate the algorithm for diagnosing respiratory sarcopenia and the efficacy of rehabilitation nutrition for preventing and treating respiratory sarcopenia and sarcopenic respiratory disability.

Conflict of interest: Ayano Nagano, Hidetaka Wakabayashi, Keisuke Maeda, Yoji Kokura, Shinjiro Miyazaki, Takashi Mori, Dai Fujiwara have nothing to disclose.

Ethical Standards: This study has been performed in accordance with the ethical standards established in the 1964 Declaration of Helsinki and later amendments.

Disclosure statement: Hidetaka Wakabayashi reports grants from JSPS KAKENHI Grant Number 19H03979, during the conduct of the study.

\section{References}

1. Kera T, Kawai H, Hirano H, Kojima M, Watanabe Y, Motokawa K, et al. Definition of Respiratory Sarcopenia With Peak Expiratory Flow Rate. J Am Med Dir Assoc. 2019;20:1021-1025. doi:10.1016/j.jamda.2018.12.013

2. Vang P, Vasdev A, Zhan WZ, Gransee HM, Sieck GC, Mantilla CB. Diaphragm muscle sarcopenia into very old age in mice. Physiol Rep. 2020;8:e14305. doi: $10.14814 /$ phy 2.14305

3. Greising SM, Mantilla CB, Medina-Martinez JS, Stowe JM, Sieck GC. Functional impact of diaphragm muscle sarcopenia in both male and female mice. Am J Physiol Lung Cell Mol Physiol. 2015;309:L46-52. doi:10.1152/ajplung.00064.2015

4. Greising SM, Mantilla CB, Gorman BA, Ermilov LG, Sieck GC. Diaphragm muscle sarcopenia in aging mice. Exp Gerontol. 2013;48:881-887. doi:10.1016/j. exger.2013.06.001

5. Ohara DG, Pegorari MS, Oliveira Dos Santos NL, de Fatima Ribeiro Silva C, Monteiro RL, Matos AP, et al. Respiratory Muscle Strength as a Discriminator of Sarcopenia in Community-Dwelling Elderly: A Cross-Sectional Study. J Nutr Health Aging. 2018;22:952-958. doi:10.1007/s12603-018-1079-4

6. Greising SM, Ottenheijm CAC, O'Halloran KD, Barreiro E. Diaphragm plasticity in aging and disease: therapies for muscle weakness go from strength to strength. J Appl Physiol (1985). 2018;125:243-253. doi:10.1152/japplphysiol.01059.2017

7. Buchman AS, Boyle PA, Wilson RS, Leurgans S, Shah RC, Bennett DA. Respiratory muscle strength predicts decline in mobility in older persons. Neuroepidemiology. 2008:31:174-180. doi:10.1159/000154930

8. Bestall JC, Paul EA, Garrod R, Garnham R, Jones PW, Wedzicha JA. Usefulness of the Medical Research Council (MRC) dyspnoea scale as a measure of disability in patients with chronic obstructive pulmonary disease. Thorax. 1999;54:581-586. doi:10.1136/thx.54.7.581

9. Ratnovsky A, Elad D, Halpern P. Mechanics of respiratory muscles. Respiratory Physiology \& Neurobiology. 2008;163:82-89. doi:https://doi.org/10.1016/j. resp.2008.04.019

10. Ju S, Lee SJ, Park MJ, Cho YJ, Jeong YY, Jeon KN, et al. Clinical importance of cross-sectional area of intercostal muscles in patients with chronic obstructive pulmonary disease. Clin Respir J. 2018;12:939-947. doi:10.1111/crj.12609

11. Fernandes L, de Oliveira IM, Fernandes P, de Souza Neto JD, Farias M, de Freitas NA, et al. Impact of Heart Transplantation on the Recovery of Peripheral and Respiratory Muscle Mass and Strength in Patients With Chronic Heart Failure. Transplant Direct. 2018;4:e395. doi:10.1097/txd.0000000000000837

12. Nakanishi N, Oto J, Ueno Y, Nakataki E, Itagaki T, Nishimura M. Change in diaphragm and intercostal muscle thickness in mechanically ventilated patients: a prospective observational ultrasonography study. J Intensive Care. 2019;7:56. doi:10.1186/s40560-019-0410-4

13. Zambon M, Greco M, Bocchino S, Cabrini L, Beccaria PF, Zangrillo A. Assessmen of diaphragmatic dysfunction in the critically ill patient with ultrasound: a systematic review. Intensive Care Med. 2017;43:29-38. doi:10.1007/s00134-016-4524-z

14. Goligher EC, Laghi F, Detsky ME, Farias P, Murray A, Brace D, et al. Measuring diaphragm thickness with ultrasound in mechanically ventilated patients: feasibility, reproducibility and validity. Intensive Care Med. 2015;41:642-649. doi:10.1007/ s00134-015-3687-3

15. Laszlo G. Standardisation of lung function testing: helpful guidance from the ATS/ ERS Task Force. Thorax. 2006;61:744-746. doi:10.1136/thx.2006.061648

16. ATS/ERS Statement on respiratory muscle testing. Am J Respir Crit Care Med. 2002; 166:518-624. doi:10.1164/rccm.166.4.518

17. Chen LK, Woo J, Assantachai P, Auyeung TW, Chou MY, Iijima K, et al. Asian Working Group for Sarcopenia: 2019 Consensus Update on Sarcopenia Diagnosis and Treatment. J Am Med Dir Assoc. 2020;21:300-307.e302. doi:10.1016/j. jamda.2019.12.012

18. Harber P. Respiratory disability: what is it, how can we measure it, what causes it and is it important? Thorax. 2009;64:280-282. doi:10.1136/thx.2008.108811

19. Harber P. Respiratory disability and impairment: what is new? Curr Opin Pulm Med 2015;21:201-207. doi:10.1097/mcp.0000000000000141

20. Torén K, Zock J-P, Kogevinas M, Plana E, Sunyer J, Radon K, et al. An international prospective general population-based study of respiratory work disability. Thorax 2009;64:339-344. doi:10.1136/thx.2008.105007

21. Quanjer PH, Stanojevic S, Cole TJ, Baur X, Hall GL, Culver BH, et al. Multi-ethnic reference values for spirometry for the 3-95-yr age range: the global lung function 2012 equations. Eur Respir J. 2012;40:1324-1343. doi:10.1183/09031936.00080312

22. Kubota M, Kobayashi H, Quanjer PH, Omori H, Tatsumi K, Kanazawa M. Reference values for spirometry, including vital capacity, in Japanese adults calculated with the LMS method and compared with previous values. Respir Investig. 2014;52:242-250. doi:10.1016/j.resinv.2014.03.003

23. van Asten L, van den Wijngaard C, van Pelt W, van de Kassteele J, Meijer A, van der Hoek W, et al. Mortality attributable to 9 common infections: significant effect of influenza A, respiratory syncytial virus, influenza B, norovirus, and parainfluenza in elderly persons. J Infect Dis. 2012;206:628-639. doi:10.1093/infdis/jis415

24. Petroianni A, Ceccarelli D, Conti V, Terzano C. Aspiration pneumonia Pathophysiological aspects, prevention and management. A review. Panminerva Med. 2006;48:231-239.

25. El-Solh AA, Sikka P, Ramadan F, Davies J. Etiology of severe pneumonia in the very elderly. Am J Respir Crit Care Med. 2001;163:645-651. doi:10.1164/ ajrccm.163.3.2005075

26. Chen HI, Kuo CS. Relationship between respiratory muscle function and age, sex, and other factors. J Appl Physiol (1985). 1989;66:943-948. doi:10.1152/ jappl.1989.66.2.943

27. Watsford ML, Murphy AJ, Pine MJ. The effects of ageing on respiratory muscle function and performance in older adults. J Sci Med Sport. 2007;10:36-44 doi: $10.1016 /$ j.jsams.2006.05.002

28. Enright PL, Kronmal RA, Manolio TA, Schenker MB, Hyatt RE. Respiratory muscle strength in the elderly. Correlates and reference values. Cardiovascular Health Study Research Group. Am J Respir Crit Care Med. 1994;149:430-438. doi:10.1164/ ajrccm.149.2.8306041

29. Lalley PM. The aging respiratory system--pulmonary structure, function and neural control. Respir Physiol Neurobiol. 2013;187:199-210. doi:10.1016/j.resp.2013.03.012

30. Bordoni B, Morabito B, Simonelli M. Ageing of the Diaphragm Muscle. Cureus 2020;12:e6645. doi:10.7759/cureus.6645

31. Nucci RAB, de Souza RR, Suemoto CK, Busse AL, Maifrino LBM, Anaruma CA, et al. Diaphragm muscle structure in the elderly: Findings from an autopsy study. Acta Histochemica. 2019;151487. doi:https://doi.org/10.1016/j.acthis.2019.151487

32. Shin HI, Kim DK, Seo KM, Kang SH, Lee SY, Son S. Relation Between Respiratory Muscle Strength and Skeletal Muscle Mass and Hand Grip Strength in the Healthy Elderly. Ann Rehabil Med. 2017;41:686-692. doi:10.5535/arm.2017.41.4.686

33. Nishimura Y, Nakata H, Matsubara M, Iwai Y, Maeda H, Yokoyama M. [Relationship between diaphragm weight and body composition]. Nihon Kyobu Shikkan Gakka Zasshi. 1996;34:501-505.

34. Jeon YK, Shin MJ, Kim MH, Mok JH, Kim SS, Kim BH, et al. Low pulmonary function is related with a high risk of sarcopenia in community-dwelling older adults: the Korea National Health and Nutrition Examination Survey (KNHANES) 20082011. Osteoporos Int. 2015;26:2423-2429. doi:10.1007/s00198-015-3152-8

35. Choe EK, Lee Y, Kang HY, Choi SH, Kim JS. Association between CT-Measured Abdominal Skeletal Muscle Mass and Pulmonary Function. J Clin Med. 2019;8:667. doi: $10.3390 / \mathrm{jcm} 8050667$

36. Son DH, Yoo JW, Cho MR, Lee YJ. Relationship Between Handgrip Strength and Pulmonary Function in Apparently Healthy Older Women. J Am Geriatr Soc. 


\section{RESPIRATORY SARCOPENIA AND SARCOPENIC RESPIRATORY DISABILITY}

2018;66:1367-1371. doi:10.1111/jgs.15410

37. Bahat G, Tufan A, Ozkaya H, Tufan F, Akpinar TS, Akin S, et al. Relation between hand grip strength, respiratory muscle strength and spirometric measures in male nursing home residents. Aging Male. 2014;17:136-140. doi:10.3109/13685538.2014.9 36001

38. Ro HJ, Kim DK, Lee SY, Seo KM, Kang SH, Suh HC. Relationship Between Respiratory Muscle Strength and Conventional Sarcopenic Indices in Young Adults: A Preliminary Study. Ann Rehabil Med. 2015;39:880-887. doi:10.5535/ arm.2015.39.6.880

39. Landi F, Salini S, Zazzara MB, Martone AM, Fabrizi S, Bianchi M, et al. Relationship between pulmonary function and physical performance among community-living people: results from Look-up 7+ study. J Cachexia Sarcopenia Muscle. 2020;11:38-45. doi: $10.1002 /$ jcsm. 12485

40. Charles A, Buckinx F, Cataldo D, Rygaert X, Gruslin B, Reginster JY, et al Relationship between peak expiratory flow and incidence of frailty, deaths and falls among nursing home residents: Results of the SENIOR cohort. Arch Gerontol Geriatr. 2019;85:103913. doi:10.1016/j.archger.2019.103913

41. Kera T, Kawai H, Hirano H, Kojima M, Fujiwara Y, Ihara K, et al. Relationships among peak expiratory flow rate, body composition, physical function, and sarcopenia in community-dwelling older adults. Aging Clin Exp Res. 2018;30:331-340. doi:10.1007/s40520-017-0777-9

42. Deniz O, Coteli S, Karatoprak NB, Pence MC, Varan HD, Kizilarslanoglu MC, et al Diaphragmatic muscle thickness in older people with and without sarcopenia. Aging Clin Exp Res. 2020; doi:10.1007/s40520-020-01565-5

43. Vidal MB, Pegorari MS, Santos EC, Matos AP, Pinto ACPN, Ohara DG. Respiratory muscle strength for discriminating frailty in community-dwelling elderly: a crosssectional study. Arch Gerontol Geriatr. 2020;89:104082. doi:https://doi.org/10.1016/j. archger.2020.104082

44. Trevisan C, Rizzuto D, Maggi S, Sergi G, Welmer AK, Vetrano DL. Cross-Sectiona and Longitudinal Associations between Peak Expiratory Flow and Frailty in Older Adults. J Clin Med. 2019;8: 1901. doi:10.3390/jcm8111901

45. Costamagna D, Costelli P, Sampaolesi M, Penna F. Role of Inflammation in Muscle Homeostasis and Myogenesis. Mediators Inflamm. 2015;2015:805172. doi: $10.1155 / 2015 / 805172$

46. Jo E, Lee SR, Park BS, Kim JS. Potential mechanisms underlying the role of chronic inflammation in age-related muscle wasting. Aging Clin Exp Res. 2012;24:412-422. doi: $10.3275 / 8464$

47. Radigan KA, Nicholson TT, Welch LC, Chi M, Amarelle L, Angulo M, et al Influenza A Virus Infection Induces Muscle Wasting via IL-6 Regulation of the E3 Ubiquitin Ligase Atrogin-1. J Immunol. 2019;202:484-493. doi:10.4049/ jimmunol.1701433

48. Supinski GS, Callahan LA. Caspase activation contributes to endotoxin-induced diaphragm weakness. J Appl Physiol (1985). 2006;100:1770-1777. doi:10.1152/ japplphysiol.01288.2005

49. Duan H, Bai H. Is Mitochondrial Oxidative Stress the Key Contributor to Diaphragm Atrophy and Dysfunction in Critically Ill Patients? Crit Care Res Pract. 2020;2020:8672939. doi:10.1155/2020/8672939

50. Komatsu R, Okazaki T, Ebihara S, Kobayashi M, Tsukita Y, Nihei M, et al. Aspiration pneumonia induces muscle atrophy in the respiratory, skeletal, and swallowing systems. J Cachexia Sarcopenia Muscle. 2018;9:643-653. doi:10.1002/jcsm.12297

51. Okazaki T, Ebihara S, Mori T, Izumi S, Ebihara T. Association between sarcopenia and pneumonia in older people. Geriatr Gerontol Int. 2020;20:7-13. doi:10.1111/ ggi.13839

52. Levine S, Kaiser L, Leferovich J, Tikunov B. Cellular adaptations in the diaphragm in chronic obstructive pulmonary disease. N Engl J Med. 1997;337:1799-1806. doi:10.1056/nejm199712183372503

53. Nosacka RL, Delitto AE, Delitto D, Patel R, Judge SM, Trevino JG, et al. Distinct cachexia profiles in response to human pancreatic tumours in mouse limb and respiratory muscle. J Cachexia Sarcopenia Muscle. 2020;11:820-837. doi:10.1002/ jcsm.12550

54. Zellner HK, Moss OA, Peterson SJ, Hicks-McGarry S, Moran E, Becker E, et al. Differences in Respiratory Muscle Strength Measures in Well-Nourished and Malnourished Hospitalized Patients. J Acad Nutr Diet. 2019;119:831-839. doi:10.1016/j.jand.2019.01.004

55. Levine S, Nguyen T, Taylor N, Friscia ME, Budak MT, Rothenberg P, et al. Rapid disuse atrophy of diaphragm fibers in mechanically ventilated humans. N Engl J Med. 2008;358:1327-1335. doi:10.1056/NEJMoa070447

56. Hermans G, Agten A, Testelmans D, Decramer M, Gayan-Ramirez G. Increased duration of mechanical ventilation is associated with decreased diaphragmatic force: a prospective observational study. Crit Care. 2010;14:R127. doi:10.1186/cc9094

57. Grosu HB, Ost DE, Lee YI, Song J, Li L, Eden E, et al. Diaphragm Muscle Thinning in Subjects Receiving Mechanical Ventilation and Its Effect on Extubation. Respir
Care. 2017;62:904-911. doi:10.4187/respcare.05370

58. Elliott JE, Greising SM, Mantilla CB, Sieck GC. Functional impact of sarcopenia in respiratory muscles. Respir Physiol Neurobiol. 2016;226:137-146. doi:10.1016/j. resp.2015.10.001

59. Roberts BM, Ahn B, Smuder AJ, Al-Rajhi M, Gill LC, Beharry AW, et al. Diaphragm and ventilatory dysfunction during cancer cachexia. FASEB J. 2013;27:2600-2610. doi:10.1096/fj.12-222844

60. Kaneko H. Association of respiratory function with physical performance, physical activity, and sedentary behavior in older adults. J Phys Ther Sci. 2020;32:92-97. doi:10.1589/jpts.32.92

61. Baig MMA, Hashmat N, Adnan M, Rahat T. The relationship of dyspnea and disease severity with anthropometric indicators of malnutrition among patients with chronic obstructive pulmonary disease. Pak J Med Sci. 2018;34:1408-1411. doi:10.12669/ pjms.346.15769

62. Vaz Fragoso CA, Beavers DP, Hankinson JL, Flynn G, Berra K, Kritchevsky SB, et al. Respiratory impairment and dyspnea and their associations with physical inactivity and mobility in sedentary community-dwelling older persons. J Am Geriatr Soc. 2014;62:622-628. doi:10.1111/jgs.12738

63. Vassilakopoulos T, Petrof BJ. Ventilator-induced diaphragmatic dysfunction. Am J Respir Crit Care Med. 2004;169:336-341. doi:10.1164/rccm.200304-489CP

64. Testelmans D, Maes K, Wouters P, Powers SK, Decramer M, Gayan-Ramirez G Infusions of rocuronium and cisatracurium exert different effects on rat diaphragm function. Intensive Care Med. 2007;33:872-879. doi:10.1007/s00134-007-0584-4

65. Maes K, Testelmans D, Cadot P, Deruisseau K, Powers SK, Decramer M, et al. Effects of acute administration of corticosteroids during mechanical ventilation on rat diaphragm. Am J Respir Crit Care Med. 2008;178:1219-1226. doi:10.1164/ rccm.200702-2960C

66. Goligher EC, Dres M, Fan E, Rubenfeld GD, Scales DC, Herridge MS, et al Mechanical Ventilation-induced Diaphragm Atrophy Strongly Impacts Clinica Outcomes. Am J Respir Crit Care Med. 2018;197:204-213. doi:10.1164/rccm.2017030536OC

67. Fujishima I, Fujiu-Kurachi M, Arai H, Hyodo M, Kagaya H, Maeda K, et al. Sarcopenia and dysphagia: Position paper by four professional organizations. Geriatr Gerontol Int. 2019;19:91-97. doi:10.1111/ggi.13591

68. Sclauser Pessoa IM, Franco Parreira V, Fregonezi GA, Sheel AW, Chung F, Reid WD. Reference values for maximal inspiratory pressure: a systematic review. Can Respir J. 2014;21:43-50. doi:10.1155/2014/982374

69. Nishimura Y, Maeda H, Tanaka K, Hashimoto A, Hashimoto Y, Yokoyama M, et al. [The effect of aging on respiratory muscle function]. Nihon Kyobu Shikkan Gakkai Zasshi. 1991;29:795-801.

70. Ohara DG, Pegorari MS, Oliveira Dos Santos NL, de Fatima Ribeiro Silva C, Oliveira MSR, Matos AP, et al. Cross-Sectional Study on the Association between Pulmonary Function and Sarcopenia in Brazilian Community-Dwelling Elderly from the Amazon Region. J Nutr Health Aging. 2020;24:181-187. doi:10.1007/s12603-019-1290-y

71. Beaumont M, Forget P, Couturaud F, Reychler G. Effects of inspiratory muscle training in COPD patients: A systematic review and meta-analysis. Clin Respir J. 2018;12:2178-2188. doi:10.1111/crj.12905

72. Templeman L, Roberts F. Effectiveness of expiratory muscle strength training on expiratory strength, pulmonary function and cough in the adult population: a systematic review. Physiotherapy. 2020;106:43-51. doi:10.1016/j.physio.2019.06.002

73. Cebrià IIM, Balasch-Bernat M, Tortosa-Chuliá M, Balasch-Parisi S. Effects of Resistance Training of Peripheral Muscles Versus Respiratory Muscles in Older Adults With Sarcopenia Who are Institutionalized: A Randomized Controlled Trial. J Aging Phys Act. 2018;26:637-646. doi:10.1123/japa.2017-0268

74. Liu K, Zhang W, Yang Y, Zhang J, Li Y, Chen Y. Respiratory rehabilitation in elderly patients with COVID-19: A randomized controlled study. Complement Ther Clin Pract. 2020;39:101166. doi:10.1016/j.ctcp.2020.101166

75. Sillen MJ, Franssen FM, Delbressine JM, Vaes AW, Wouters EF, Spruit MA Efficacy of lower-limb muscle training modalities in severely dyspnoeic individuals with COPD and quadriceps muscle weakness: results from the DICES trial. Thorax. 2014;69:525-531. doi:10.1136/thoraxjnl-2013-204388

76. Chen Y, Niu M, Zhang X, Qian H, Xie A, Wang X. Effects of home-based lower limb resistance training on muscle strength and functional status in stable Chronic obstructive pulmonary disease patients. J Clin Nurs. 2018;27:e1022-e1037. doi:10.1111/jocn.14131

77. Jeon YK, Shin MJ, Kim CM, Lee BJ, Kim SH, Chae DS, et al. Effect of Squa Exercises on Lung Function in Elderly Women with Sarcopenia. J Clin Med. 2018;7:167. doi:10.3390/jcm7070167

78. Nyberg A, Lindström B, Rickenlund A, Wadell K. Low-load/high-repetition elastic band resistance training in patients with COPD: a randomized, controlled, multicenter trial. Clin Respir J. 2015;9:278-288. doi:10.1111/crj.12141

79. Chen HT, Wu HJ, Chen YJ, Ho SY, Chung YC. Effects of 8-week kettlebell training 
on body composition, muscle strength, pulmonary function, and chronic low-grade inflammation in elderly women with sarcopenia. Exp Gerontol. 2018;112:112-118. doi:10.1016/j.exger.2018.09.015

80. Hoffman M, Chaves G, Ribeiro-Samora GA, Britto RR, Parreira VF. Effects of pulmonary rehabilitation in lung transplant candidates: a systematic review. BMJ Open. 2017;7:e013445. doi:10.1136/bmjopen-2016-013445

81. Greulich T, Kehr K, Nell C, Koepke J, Haid D, Koehler U, et al. A randomized clinical trial to assess the influence of a three months training program (gym-based individualized vs. calisthenics-based non-invidualized) in COPD-patients. Respir Res. 2014;15:36. doi:10.1186/1465-9921-15-36

82. Costes F, Gosker H, Feasson L, Desgeorges M, Kelders M, Castells J, et al. Impaired exercise training-induced muscle fiber hypertrophy and Akt/mTOR pathway activation in hypoxemic patients with COPD. J Appl Physiol (1985). 2015;118:1040-1049. doi:10.1152/japplphysiol.00557.2014

83. Ferreira IM, Brooks D, White J, Goldstein R. Nutritional supplementation for stable chronic obstructive pulmonary disease. Cochrane Database Syst Rev. 2012;12:Cd000998. doi:10.1002/14651858.CD000998.pub3

84. Khan NA, Kumar N, Daga MK. Effect of Dietary Supplementation on Body Composition, Pulmonary Function and Health-Related Quality of Life in Patients with Stable COPD. Tanaffos. 2016;15:225-235.

85. van der Meij BS, Langius JA, Spreeuwenberg MD, Slootmaker SM, Paul MA, Smit $\mathrm{EF}$, et al. Oral nutritional supplements containing n-3 polyunsaturated fatty acids affect quality of life and functional status in lung cancer patients during multimodality treatment: an RCT. Eur J Clin Nutr. 2012;66:399-404. doi:10.1038/ejen.2011.214

86. Martínez-Arnau FM, Fonfría-Vivas R, Buigues C, Castillo Y, Molina P, Hoogland AJ et al. Effects of Leucine Administration in Sarcopenia: A Randomized and Placebocontrolled Clinical Trial. Nutrients. 2020;12:932. doi: 10.3390/nu12040932

87. van de Bool C, Rutten EPA, van Helvoort A, Franssen FME, Wouters EFM, Schols A. A randomized clinical trial investigating the efficacy of targeted nutrition as adjunct to exercise training in COPD. J Cachexia Sarcopenia Muscle. 2017;8:748-758. doi: $10.1002 /$ jcsm. 12219
88. Aldhahir AM, Rajeh AMA, Aldabayan YS, Drammeh S, Subbu V, Alqahtani JS, et al. Nutritional supplementation during pulmonary rehabilitation in COPD: A systematic review. Chron Respir Dis. 2020;17:1479973120904953. doi: $10.1177 / 1479973120904953$

89. Agrelli TF, Borges MC, Cunha F, Silva É MCD, Terra Júnior JA, Crema E. Combination of preoperative pulmonary and nutritional preparation for esophagectomy. Acta Cir Bras. 2018;33:67-74. doi:10.1590/s0102865020180010000007

90. Hashida N, Shamoto H, Maeda K, Wakabayashi H, Suzuki M, Fujii T. Rehabilitation and nutritional support for sarcopenic dysphagia and tongue atrophy after glossectomy: A case report. Nutrition. 2017;35:128-131. doi:10.1016/j. nut.2016.11.003

91. Maeda K, Akagi J. Treatment of Sarcopenic Dysphagia with Rehabilitation and Nutritional Support: A Comprehensive Approach. J Acad Nutr Diet. 2016;116:573577. doi:10.1016/j.jand.2015.09.019

92. Wakabayashi H, Uwano R. Rehabilitation Nutrition for Possible Sarcopenic Dysphagia After Lung Cancer Surgery: A Case Report. Am J Phys Med Rehabil. 2016;95:e84-89. doi:10.1097/phm.0000000000000458

93. Someya R, Wakabayashi H, Hayashi K, Akiyama E, Kimura K. Rehabilitation Nutrition for Acute Heart Failure on Inotropes with Malnutrition, Sarcopenia, and Cachexia: A Case Report. J Acad Nutr Diet. 2016;116:765-768. doi:10.1016/j. jand.2015.11.002

94. Nagano A, Nishioka S, Wakabayashi H. Rehabilitation Nutrition for Iatrogenic Sarcopenia and Sarcopenic Dysphagia. J Nutr Health Aging. 2019;23:256-265. doi 10.1007/s12603-018-1150-1.

95. Kuzuya M, Sugimoto K, Suzuki T, Watanabe Y, Kamibayashi K, Kurihara T, et al Chapter 3 Prevention of sarcopenia. Geriatr Gerontol Int. 2018;18 Suppl 1:23-27. doi:10.1111/ggi.13321

96. Arai H, Wakabayashi H, Yoshimura Y, Yamada M, Kim H, Harada A. Chapter 4 Treatment of sarcopenia. Geriatr Gerontol Int. 2018;18 Suppl 1:28-44. doi:10.1111/ ggi.13322 